\title{
Hepatitis C virus genotype 3a with phylogenetically distinct origin is circulating in Pakistan
}

\author{
Irshad-ur Rehman, Muhammad Idrees", Muhammad Ali, Liaqat Ali, Sadia Butt, Abrar Hussain, \\ Haji Akbar, Samia Afzal
}

\begin{abstract}
Background: Hepatitis C virus (HCV) is one of the leading causes of viral hepatitis worldwide and its genotype 3a is predominant in vast areas of Pakistan.

Findings: The present study reports the first full sequence of HCV 3a isolate PK-1 from Pakistan. This nucleotide sequence was compared with six other HCV genotype 3a full length sequences from different regions of the world by using statistical methods of phylogenetic analysis.

Conclusion: The nucleotide difference of these seven sequences shows that HCV genotype 3a of phylogenetically distinct origin is circulating in Pakistan.
\end{abstract}

\section{Findings}

Hepatitis $\mathrm{C}$ virus (HCV) is leading cause of chronic liver disease [1] with estimated 170-200 million infected persons worldwide [2] including approximately 17 million in Pakistan [3]. It is positive single stranded RNA virus first isolated in 1819 and is a member of Flaviviridae $[2,4]$. The HCV genome is about $9.6 \mathrm{~kb}$ in length consisting of single open reading frame encoding a polyprotein of 3,000 amino acids and non-translated regions located at the 5'and 3 ' terminus [5].

The relative prevalence of $\mathrm{HCV}$ genotypes varies with the geographic area but genotypes 1, 2 and 3 have worldwide distribution. $1 \mathrm{a}$ and $1 \mathrm{~b}$ are the most widespread genotypes in the Europe, [6] USA, [7] and Japan [8]. HCV subtype 3a is the most common genotype circulating in India [9], Nepal [10] and Pakistan [11]. HCV genotype 4 prevailing in the Middle East and North Africa [12], and genotypes 5 and 6 appears to be most common to South Africa and Hong Kong, respectively [13]. Genetic analysis of HCV genotype $3 \mathrm{a}$ is very important as it is very sensitive to interferon therapy compared to the other genotypes.

Butt and colleagues [2] showed that HCV 3a has been the predominant genotype (causing disease in $62 \%$ -

\footnotetext{
* Correspondence: idreeskhan96@yahoo.com

* Correspondence: idreeskhan96@yahoo.com Biology, University of the Punjab, 87-West Canal Bank Road Thokar Niaz Baig Lahore-53700, Pakistan
}

(C) 2011 Rehman et al; licensee BioMed Central Ltd. This is an Open Access article distributed under the terms of the Creative Commons Attribution License (http://creativecommons.org/licenses/by/2.0), which permits unrestricted use, distribution, and reproduction in any medium, provided the original work is properly cited.
$70 \%$ patients) in Pakistan based on the last ten years data (2000-2009), which shows that this genotype has been successfully spreading in Pakistan. However, it has not been well characterized genomically. For this purpose, serum sample from patient infected with $\mathrm{HCV}$ was obtained and consensus sequence of HCV genotype 3a isolate PK-1 was determined from cDNA using various modified methods [14,15]. In the present study, we report the first full sequence of $\mathrm{HCV}$ isolate PK-1 (9474 nucleotides) from Pakistan. This genomic sequence is phylogenetically distinct from the $\mathrm{HCV}$ genotype $3 \mathrm{a}$ isolates sequenced in the rest of the countries like USA, New Zealand, Italy, Australia and Germany (Table 1).

Phylogenetic analysis of the isolate PK-1 and all the full length $\mathrm{HCV}$ genotype $3 \mathrm{a}$ genomes $(\mathrm{n}=7)$ in the GenBank database (Table 1) by using MEGA4 software package. Two different methods (UPGMA method and Neighbor Joining (NJ) method) of the phylogenetic analysis were used as described previously [16]. Evolutionary distances were also estimated by using methods previously reported by Tamura et al [16].

The full length genomic sequences of $\mathrm{HCV} 3 \mathrm{a}$ reported from USA, New Zealand, Italy and Australia were clustered together while Pakistani isolate is shown phylogenetically distinct by 500 replicates bootstrap analysis (Figure 1). Estimates of evolutionary divergence between the sequences (Table 1) shows that the Pakistani isolate have evolutionary distance of $0.085-0.103$ to the 
Table 1 List of the hepatitis C virus genotype $3 a$ sequences used in the analysis.

\begin{tabular}{llll}
\hline $\begin{array}{l}\text { S. } \\
\text { No. }\end{array}$ & $\begin{array}{l}\text { GenBank accession } \\
\text { No. }\end{array}$ & Country & Strain* \\
\hline $\mathbf{1}$ & D17763 & $\begin{array}{l}\text { New } \\
\text { Zealand }\end{array}$ & 2005-NZL1 \\
& & Germany & 2005 \\
$\mathbf{2}$ & X76918 & USA & 2005-HCV-K3a/650 \\
$\mathbf{3}$ & D28917 & Australia & 2007-CB \\
$\mathbf{4}$ & AF046866 & Pakistan & 2010-PK-1 \\
$\mathbf{5}$ & Gu294484/Pk & Italy & 2010-S52 \\
$\mathbf{6}$ & GU814263 & Italy & 2010-S52 (Synthetic \\
$\mathbf{7}$ & GU814264 & & construct) \\
\hline
\end{tabular}

*Year of publication of the genome in GenBank and strain if assigned. GenBank accession numbers, place of isolation, isolate name and publishing year are also mentioned. rest of all the full length sequences however, the average distance between all these sequences is $0.0655 \pm 0.0071$ (Table 2 ). The analysis also suggests that PK-1 and American isolate (D28917) are the earliest phylogenetic representatives of the HCV genotype 3a that has been successfully spreading in Pakistan and USA respectively, while the rest of the isolates are their late derivatives spreading in Germany, Italy, New Zealand and Australia. As 3a is the predominant genotype in Pakistan, its sequencing data and evolutionary analysis will help in evaluation and development of new antiviral therapies and possible vaccine development. Moreover, the association of $\mathrm{HCV}$ genotype 3a full length nucleotide sequences with the epidemiology, severity of disease and its response to interferon therapy needs to be evaluated.

(a)
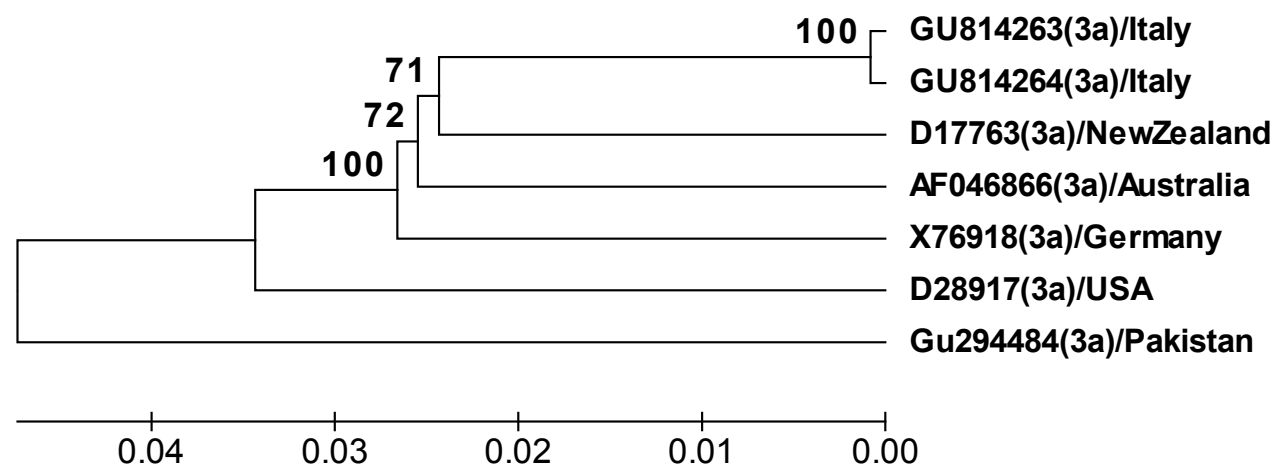

(b)

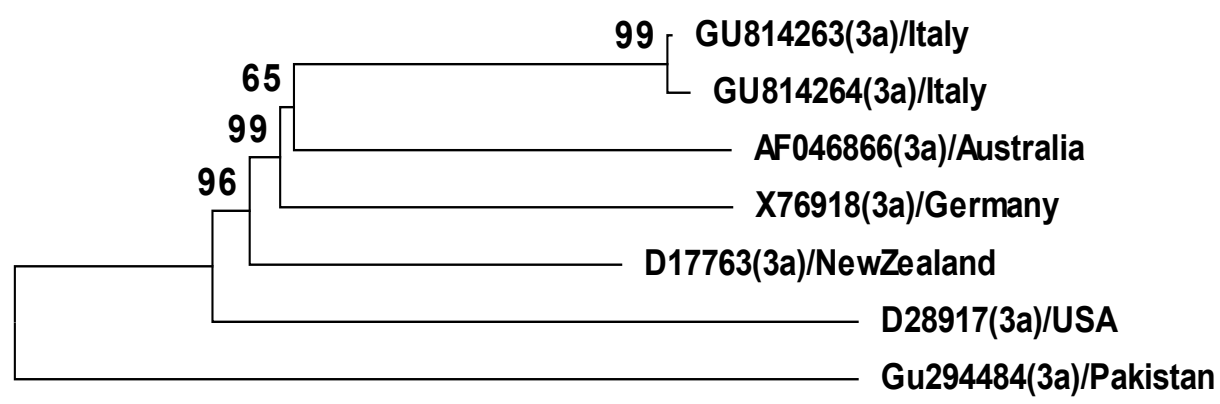

0.01

Figure 1 The bootstrap original phylogenetic tree of hepatitis C virus (HCV) genotype 3a isolates from different regions of the world based on complete genome sequences inferred from $\mathbf{5 0 0}$ replicates representing the evolutionary relationship. Branches corresponding to partitions reproduced in less than $50 \%$ bootstrap replicates are clustered together while; branch lengths are measured by the scale in the same units as those of the evolutionary distances. GenBank accession numbers, genotype and place of isolation are mentioned for all the isolates. (a) UPGMA analysis (b) Neighbour-Joining method describing the evolutionary relationship between the HCV full length sequences. 
Table 2 Estimates of evolutionary divergence between sequences with standard error estimates.

\begin{tabular}{llll}
\hline Sequence 1 & Sequence 2 & Dist & Std. Err \\
\hline Gu294484(3a)/Pakistan & D17763(3a)/New Zealand & 0.0858383 & 0.0100783 \\
Gu294484(3a)/Pakistan & GU814263(3a)/Italy & 0.0929113 & 0.0108032 \\
D17763(3a)/New Zealand & GU814263(3a)/Italy & 0.0480462 & 0.0056442 \\
Gu294484(3a)/Pakistan & GU814264(3a)/Italy & 0.0945252 & 0.0110770 \\
D17763(3a)/New Zealand & GU814264(3a)/Italy & 0.0492012 & 0.0058641 \\
GU814263(3a)/Italy & GU814264(3a)/Italy & 0.0016043 & 0.0004740 \\
Gu294484(3a)/Pakistan & AF046866(3a)/Australia & 0.0965145 & 0.0109635 \\
D17763(3a)/New Zealand & AF046866(3a)/Australia & 0.0520425 & 0.0061060 \\
GU814263(3a)/Italy & AF046866(3a)/Australia & 0.0499546 & 0.0059291 \\
GU814264(3a)/Italy & AF046866(3a)/Australia & 0.0508833 & 0.0061427 \\
Gu294484(3a)/Pakistan & X76918(3a)/Germany & 0.0945054 & 0.0110161 \\
D17763(3a)/New Zealand & X76918(3a)/Germany & 0.0533185 & 0.0065799 \\
GU814263(3a)/Italy & X76918(3a)/Germany & 0.0518464 & 0.0066160 \\
GU814264(3a)/Italy & X76918(3a)/Germany & 0.0526615 & 0.0067952 \\
AF046866(3a)/Australia & X76918(3a)/Germany & 0.0550679 & 0.0067483 \\
Gu294484(3a)/Pakistan & D28917(3a)/USA & 0.1032085 & 0.0078749 \\
D17763(3a)/New Zealand & D28917(3a)/USA & 0.0673865 & 0.0075880 \\
GU814263(3a)/Italy & D28917(3a)/USA & 0.06666617 & 0.0077599 \\
GU814264(3a)/Italy & D28917(3a)/USA & 0.0676199 & 0.0080246 \\
AF046866(3a)/Australia & D28917(3a)/USA & 0.0704518 & 0.0083935 \\
X76918(3a)/Germany & D28917(3a)/USA & 0.0712210 & \\
\hline
\end{tabular}

* All the positions containing missing data and gapes were eliminated.

\section{Acknowledgements \\ Sources of support: This work was partially supported by the Higher Education Commission of Pakistan.}

\section{Authors' contributions}

MI conceived of the study. IR, SB, SA, HA and AH performed the sequencing studies. MA and IR organized the data and drafted the manuscript. SB, LA and $\mathrm{AH}$ helped MA in sequence alignment and evolutionary analysis. All the authors read and approved the final manuscript.

\section{Competing interests}

The authors declare that they have no competing interests.

Received: 5 December 2010 Accepted: 6 January 2011

Published: 6 January 2011

\section{References}

1. Poynard T, Ratziu V, Benhamou Y, Opolon P, Cacoub P, Bedossa P: Natural history of HCV infection. Best Pract Res Clin Gastroenterol 2000, 14:211-228.

2. Butt S, Idrees M, Akbar H, Rehman I, Awan Z, Afzal S, et al: The changing epidemiology pattern and frequency distribution of hepatitis $C$ virus in Pakistan. Infect Genet Evol 2010, 10(5):595-600

3. Idrees $M$, Lal A, Naseem M, Khalid M: High prevalence of hepatitis C virus infection in the largest province of Pakistan. J Dig Dis 2008, 9:95-103.

4. Ogata N, Alter HJ, Miller RH, Purcell RH: Nucleotide sequence and mutation rate of the $\mathrm{H}$ strain of hepatitis $\mathrm{C}$ virus. Proc Natl Acad Sci USA 1991, 88:3392-3396.

5. Lemon SM, Walker CM, Alter MJ, Yi M: Fields Virology. Lippincot Williams and Wilkins, Philadelpia. Hepatitis C virus; 2007, 1253-1304.

6. Dusheiko G, Main J, Thomas H: Ribavirin treatment for patients with chronic hepatitis C: results of a placebo-controlled study. Hepatology 1994, 25:591-598.

7. Zein NN, Persing DH: Hepatitis C Genotypes: current trends and future implications. Mayo Clin Proc 1996, 71:458-462.
8. Takada NS, Takase S, Takada A, Date T: Differences in the hepatitis C virus genotypes in different countries. J Hepatol 1993, 17:277-283.

9. Singh B, Verma M, Verma K: Markers for transfusion associated hepatitis in North Indian blood donors: prevalence and trends. Jpn J Infec Dis 2004, 57:49-51.

10. Tokita H, Shrestha SM, Okamoto H, Sakamoto M, Horikita M, et al: Hepatitis $C$ virus variants from Nepal with novel genotypes and their classification into the third major group. J Gen Virol 1994, 75:931-936.

11. Idrees $M$, Riazuddin S: Frequency distribution of hepatitis $C$ virus genotypes in different geographical regions of Pakistan and their possible routes of transmission. BMC Infect Dis 2008, 8:69.

12. Abdulkarim AS, Zein NN, Germer JJ, Kolbert CP, Kabbani L, Krajnik KL: Hepatitis $C$ virus genotypes and hepatitis $G$ virus in hemodialysis patients from Syria: identification of two novel hepatitis $C$ virus subtypes. Am J Trop Med Hyg 1998, 59:571-576.

13. Simmonds $P$, Holmes EC, Cha TA, Chan SW, McOmish F, Irvine B: Classification of hepatitis $C$ virus into six major genotypes and a series of subtypes by phylogenetic analysis of the NS-5 region. J Gen Virol 1993, 74:2391-2399.

14. Bracho MA, Saludes V, Martro E, Bargallo A, González-Candelas F, Ausina V: Complete genome of a European hepatitis $C$ virus subtype $1 \mathrm{~g}$ isolate: phylogenetic and genetic analyses. Virol J 2008, 5:72.

15. Chamberlain RW, Adams N, Saeed AA, Simmonds P, Elliott RM: Complete nucleotide sequence of a type 4 hepatitis $C$ virus variant, the predominant genotype in the Middle East. J Gen Virol 1997, 78:1341-1347.

16. Tamura K, Dudley J, Nei M, Kumar S: MEGA4: Molecular Evolutionary Genetics Analysis (MEGA) software version 4.0. Mol Biol Evol 2007 , 24:1596-1599.

doi:10.1186/1479-0556-9-2

Cite this article as: Rehman et al: Hepatitis C virus genotype 3a with phylogenetically distinct origin is circulating in Pakistan. Genetic Vaccines and Therapy 2011 9:2. 